\title{
Adaptabilidade e Estabilidade de Cultivares de Milho para Silagem em Relação à Produção de Matéria Seca Degradável no Rúmen
}

\author{
Jackson Silva e Oliveira1, Reinaldo de Paula Ferreira ${ }^{1}$, Cosme Damião Cruz ${ }^{2}$, Antônio \\ Vander Pereira1, Fernando César Ferraz Lopes ${ }^{3}$
}

\begin{abstract}
RESUMO - Foram avaliadas oito cultivares de milho para uso na forma de silagem. Os ensaios foram conduzidos em cinco localidades e a característica estudada foi a produção de matéria seca degradável no rúmen $(\mathrm{kg} / \mathrm{ha})$. Verificou-se a existência de interação genótipo $\times$ ambiente significativa para esta característica, demonstrando o comportamento diferencial das variedades para as variações ambientais. A variedade BR HT2X, apesar de ter apresentado elevada produtividade, foi a que mais contribuiu para a interação genótipo $\times$ ambiente, porém apresentou comportamento imprevisível, sendo, por isso, recomendada para situações de alto nível tecnológico, em que os efeitos de condições adversas podem ser minimizados. As variedades BR 205 e AGM 2010 destacaram-se pela alta produtividade e foram recomendadas como materiais de ampla adaptabilidade e alta previsibilidade. As variedades BR CMS 473 e, principalmente, BR 106 apresentaram produtividades inferiores, porém com comportamento previsível, demonstrando invariância de resposta à melhoria ambiental, o que caracteriza sua rusticidade.
\end{abstract}

Palavras-chave: interação genótipo $\times$ ambiente, silagem, Zea mays $\mathrm{L}$

\section{Adaptability and Stability of Maize Cultivars for Silage in Relation to the Rumen Degradable Dry Matter Yield}

\begin{abstract}
A study was conducted in five locations to evaluate the silage potential of eight maize cultivars estimated by the rumen degradable dry matter yield $(\mathrm{kg} / \mathrm{ha})$. A significant interaction of genotype $\times$ environment was found for this characteristic, indicating a differential behavior of the varieties when environmental conditions changed. Although the variety BR HT2X had a high dry matter yield, it was the one which contributed most to the genotype $\times$ environment interaction. Nevertheless, it presented unpredictable behavior, thus it is recommended for situations of high levels of technology when effects of unfavorable conditions are minimized. The varieties BR 205 and AGM 2010 outyielded the others and are recommended as materials of wide adaptability and high predictability. The varieties BR CMS 473 and mainly BR 106 presented lower yields. However, they exhibited a predictable behavior, indicating invariant response to environmental improvement which characterizes rusticity.
\end{abstract}

Key Words: genotype $\mathrm{x}$ environment interaction, silage, Zea mays L

\section{Introdução}

A silagem de milho é um alimento volumoso utilizado, durante todo o ano, na maioria dos sistemas de produção de leite que adotam o confinamento e, como suplemento, nos sistemas de produção a pasto. Cultivares destinadas à ensilagem devem apresentar elevada produção de matéria seca/ha, ser ricos em carbohidratos solúveis, produzir silagem de bom valor nutritivo e permitir a maximização do consumo pelos animais (ROTH e UNDERSANDER,1995). A primeira característica possibilita menor custo por tonelada de material e as duas últimas, melhor desempenho animal e redução no uso de concentrados.

A capacidade de produção de matéria seca (MS/ha) de uma cultivar não é suficiente para avaliá-la em seu uso como silagem. É necessária a determinação da qualidade da matéria seca produzida. Sabe-se que existe alta correlação entre o valor nutritivo de uma cultivar de milho e o de sua silagem (HUNT et al.,1992). Dessa maneira, avaliando-se a planta fresca, indiretamente, estima-se a qualidade da silagem que se pode obter com aquela planta. Atualmente, uma das formas de se avaliar o valor nutritivo é por meio da digestibilidade da planta inteira, uma vez que, teoricamente, uma amostra do material analisado combina o porcentual e a qualidade de suas diferentes partes (OLIVEIRA et al.,1997).

As análises de digestibilidade in vitro mais utilizadas são determinadas com base na matéria seca (DIVMS) ou na matéria orgânica (DIVMO) do alimento. Entretanto, estas análises são caras e demo-

\footnotetext{
1 Eng. Agr., Pesquisador da Embrapa Gado de Leite. Rua Eugênio do Nascimento, 610 - Dom Bosco - 36038-330 - Juiz de Fora, MG

2 Eng. Agr., Prof. Titular, Universidade Federal de Viçosa, Dep. de Biologia Geral, 36570-000 - Viçosa, MG.

3 Eng. Agr., Técnico especializado da Embrapa Gado de Leite. Rua Eugênio do Nascimento, 610 - Dom Bosco - $36038-330$ - Juiz de Fora, MG.
} 
radas, tornando difícil a sua utilização quando se tem grande número de amostras. Outro método usado para se estimar a digestibilidade e processar, simultaneamente, grande número de amostras é por meio da estimativa da quantidade de matéria seca ou matéria orgânica, que desaparece quando o alimento permanece por determinado período de tempo no rúmen. Alta correlação foi encontrada entre esses dois parâmetros por HUNT et al. (1992), ou seja, entre digestibilidade in vitro e degradabilidade. Esses autores utilizaram 24 horas como tempo de permanência, pelo fato de ser esse o tempo médio que o alimento permanece no rúmen de uma vaca produzindo $20 \mathrm{~kg} /$ dia de leite. Considerando-se a digestibilidade como uma das mais importantes características de uma forragem, a produção de matéria seca degradável no rúmen é uma das informações que pode ser usada para escolher uma cultivar de milho para silagem.

Apesar do bom desempenho que uma variedade pode apresentar quanto à produção de matéria seca degradável no rúmen, é necessário que ela demonstre também, para esta característica, quando cultivada, resposta à melhoria do ambiente e previsibilidade. Entretanto, por efeito da interação genótipo $\times$ ambiente, muitas vezes, uma variedade superior em determinadas condições ambientais pode não manter esta superioridade em outro ambiente. Assim, o estudo pormenorizado do comportamento de uma variedade, ante as variações ambientais, tem sido de grande importância, por permitir a recomendação e utilização mais eficiente do material genético disponível.

Estudos sobre adaptabilidade e estabilidade têm sido empregados no melhoramento de plantas, para avaliação do rendimento de grãos ou frutos, em diversas culturas (CARVALHO et al., 1995; SILVA et al.,1995). Entretanto, esses estudos são raros em plantas forrageiras, sendo, portanto, de grande interesse científico o desenvolvimento de conhecimento nesta área. $\mathrm{O}$ objetivo deste trabalho foi avaliar a adaptabilidade e estabilidade da produção de matéria seca degradável no rúmen em oito cultivares de milho destinadas à produção de silagem.

\section{Materiais e Métodos}

Foram avaliadas oito cultivares de milho para ensilagem (AGM 2010, BR 106, BR 201, BR 205, BR 206, BR HT2X, BR 92HD1 e BR CMS 473) em relação à produção de matéria seca degradável no rúmen. $\mathrm{O}$ estudo foi conduzido em Minas Gerais (Capinópolis, Coronel Pacheco e Coimbra), Rio de Janeiro (Valença) e Paraná (Castro). O delineamento utilizado foi blocos ao acaso, com quatro repetições. Cada parcela foi constituída por cinco linhas de $7 \mathrm{~m}$ de comprimento, espaçadas de $0,80 \mathrm{~m}$. As duas linhas externas e $1 \mathrm{~m}$ de cada extremidade das três linhas centrais foram usadas como bordadura e, também, para fazer as avaliações do ponto de grão para a colheita.

A colheita foi feita quando os grãos se encontravam no estádio farináceo. As plantas da área útil foram cortadas a $10 \mathrm{~cm}$ de altura e pesadas para estimar a produção de matéria verde. Após a pesagem, cinco plantas foram retiradas aleatoriamente e separadas em grãos, sabugo e fração verde ( $\mathrm{FV}=$ colmo + folhas + palhas das espigas). Todo este material foi imediatamente pesado e picado para se determinar o peso da amostra seca ao ar (SILVA, 1990). Após a secagem ao ar, as amostras foram moídas e passadas em peneira de $5 \mathrm{~mm}$. Foram feitas amostras compostas para cada uma das estruturas (grão, sabugo e FV) a partir das quatro repetições. Após a determinação da matéria seca, amostras de cada cultivar foram colocadas em sacos de náilon e incubadas no rúmen de quatro vacas durante 24 horas, de acordo com a metodologia sugerida por NOCEK (1988). Com essa técnica, estimou-se a degradabilidade in situ da matéria seca de cada fração após 24 horas de incubação (DISMS-24) e, posteriormente, a DISMS-24 da planta inteira.

Combinando-se as informações de DISMS-24 da planta toda e a produção de matéria seca/ha, foi feita a estimativa do potencial de cada material para produzir matéria seca degradável após 24 horas de permanência no rúmen.

Os dados foram submetidos à análise de variância, obtendo-se, em cada local, estimativas da média e coeficiente de variação $(\mathrm{CVe})$ e de determinação genotípica $\left(\mathrm{H}^{2}\right)$. Identificada a homogeneidade de variância residual, procedeu-se à análise de variância conjunta, conforme o modelo:

$$
\mathrm{Y}_{\mathrm{ijk}}=\mu+\mathrm{B} / \mathrm{A}_{\mathrm{jk}}+\mathrm{G}_{\mathrm{i}}+\mathrm{GA}_{\mathrm{ij}}+\varepsilon_{\mathrm{ijk}}
$$

em que $Y_{\mathrm{ijk}}$ é o valor da degradabilidade da variedade $\mathrm{i}(\mathrm{i}=1,2, . .8)$, no local $\mathrm{j}(\mathrm{j}=1,2, . .5)$ e na repetição $\mathrm{k} \quad(\mathrm{k}=1,2, \ldots 4) ; \mu$ corresponde à média geral do ensaio; $\mathrm{B} / \mathrm{A}_{\mathrm{jk}}$ é o efeito aleatório do bloco $\mathrm{k}$ no ambiente $j ; \mathrm{G}_{\mathrm{i}}$ é o efeito fixo do genótipo (variedade) $\mathrm{i} ; \mathrm{A}_{\mathrm{j}}$ é o efeito aleatório de ambiente $\mathrm{j} ; \mathrm{GA}_{\mathrm{ij}}$ é o efeito aleatório da interação de primeira ordem do genótipo i com o ambiente $\mathrm{j}$; e $\varepsilon_{\mathrm{ijk}}$ corresponde ao erro associado a cada observação.

Para avaliação da adaptabilidade e estabilidade, utilizaram-se as seguintes metodologias:

a) Método proposto por PLAISTED e PETERSON (1959) 
232 Rev. bras. zootec.

$\mathrm{Na}$ metodologia proposta por esses autores, o estimador do parâmetro que descreve a estabilidade (Wi) é a média aritmética dos componentes de variância da interação entre pares de genótipos $\times$ ambientes $\left(\boldsymbol{\sigma}_{g a_{i j}}^{2}\right)$, que envolve determinado genótipo. Quantifica-se a contribuição relativa de cada genótipo para a interação genótipos $\times$ ambientes, expressa em termos do componente de variância $\sigma_{g a}^{2}$, e identificam-se os de maior estabilidade, por meio de:

$$
W_{i}=\frac{1}{g-1}\left[\sum_{i^{\prime}} \hat{\sigma}_{g a_{i^{\prime}}}^{2}\right]
$$

$\mathrm{e}$

$$
\mathrm{W}_{1}+\mathrm{W}_{2}+\ldots .+\mathrm{Wg}=g \hat{\sigma}_{g a}^{2}
$$

b) Metodologia de EBERHART e RUSSELL (1966)

Nesta metodologia é adotado o seguinte modelo de regressão linear:

$$
Y_{i j}=\beta_{\text {oi }}+\beta_{1 i} l_{j}+\delta_{i j}+\bar{\varepsilon}_{i j}
$$

em que $Y_{i j}$ é a média do genótipo (variedade) i no ambiente $\mathrm{j} ; \beta_{\mathrm{oi}}$ eqüivale à média geral do genótipo $\mathrm{i} ; \beta_{1 \mathrm{i}}$ corresponde ao coeficiente de regressão linear, cuja estimativa representa a resposta do i-ésimo genótipo à variação do ambiente $\mathrm{j} ; \mathrm{I}_{\mathrm{j}}$ é definido como o índice ambiental codificado; $\delta_{\mathrm{ij}}$ eqüivale aos desvios da regressão; e $\bar{\varepsilon}_{\mathrm{ij}}$ corresponde ao erro experimental médio.

As estimativas do parâmetro de adaptabilidade são dadas pela média da variedade $\left(\beta_{\mathrm{o}}\right)$ e pelo coeficiente de regressão linear $\left(\beta_{1 i}\right)$. Nesta metodologia entende-se por adaptabilidade a capacidade do genótipo de responder à melhoria do ambiente. São de adaptabilidade geral os genótipos com $\beta_{1 \mathrm{i}}=1$, adaptabilidade específica a ambientes favoráveis aqueles com $\beta_{1 i}>1$ e adaptabilidade específica a ambientes desfavoráveis aqueles com $\beta_{1 \mathrm{i}}<1$.

A estimativa dos parâmetros de estabilidade é dada por $\sigma_{d i}^{2}=\sum \delta_{i j}^{2} /(a-2)$, sendo a o número de ambientes. Nesta metodologia a estabilidade refere-se à previsibilidade do genótipo em relação ao modelo de regressão linear. Assim, são considerados cultivares estáveis (ou previsíveis) aqueles com desvio não-significativos e instáveis (ou não-previsíveis), aqueles com desvios singificativos. Todas as análises estatísticas foram feitas utilizando-se o programa computacional GENES (CRUZ, 1997).

\section{Resultados e Discussão}

$\mathrm{Na}$ Tabela 1 são apresentados os resultados da análise de variância feita em cada local estudado. Veri- fica-se a existência de variabilidade significativa em todos os locais, exceto em Coronel Pacheco. Este fato já revela a existência de interação significativa, demonstrando a existência de comportamento diferencial na resposta das variedades em cada condição experimental.

Em Coronel Pacheco, constatou-se que a média da produção de matéria seca degradável no rúmen foi mais elevada $(7.172,67 \mathrm{~kg} / \mathrm{ha})$, mas a precisão experimental foi baixa. A variabilidade genética manifestada neste ambiente foi nula, indicando não haver diferença entre os materiais testados. A precisão experimental também foi baixa em Valença, porém, detectou-se variabilidade genética neste ambiente.

Para os demais ambientes (Coimbra, Capinópolis e Castro), verificou-se boa precisão experimental, com coeficientes de variação $(\mathrm{CV})$ inferiores a $12,5 \%$ e de determinação genotípica $\left(\mathrm{H}^{2}\right)$ superiores a $79 \%$. Assim, foi possível discriminar os materiais avaliados quanto à sua superioridade genética relativa à digestibilidade, com boa acurácia. A avaliação do coeficiente de determinação permitiu a inferência sobre a natureza da variabilidade fenotípica manifestada e sobre a correlação entre o valor fenotípico mensurado e o verdadeiro valor genético das variedades comparadas. Altos coeficientes de determinação, como os verificados nos locais estudados, exceto para Coronel Pacheco, indicam que a identificação dos materiais superiores, a partir de suas médias fenotípicas, é feita com base no comportamento genético, sendo, portanto, de grande credibilidade.

$\mathrm{Na}$ Tabela 2 é apresentado o resultado da análise de variância conjunta. Verifica-se variabilidade significativa para as fontes de variações relacionadas com genótipos, ambientes e interação genótipos $\times$ ambientes. A significância observada para ambiente linear indica a presença de variações significativas no ambiente para proporcionar alterações nas médias dos genótipos.

Tabela 1 - Resumo da análise de variância, por local, para a característica produção de matéria seca degradável no rúmen

Table 1 - $\quad$ ANOVA results, by locations, for the rumen degradable dry matter yield characteristc

\begin{tabular}{lcccc}
\hline $\begin{array}{l}\text { Local } \\
\text { Place }\end{array}$ & $\mathrm{F}$ & $\begin{array}{c}\text { Média } \\
\text { Mean }\end{array}$ & $\mathrm{CV}_{\mathrm{e}}$ & $\mathrm{H}^{2}$ \\
\hline Coronel Pacheco & $1,50^{\mathrm{ns}}$ & 7172,67 & 21,02 & 0,33 \\
Valença & $3,68^{* *}$ & 6167,45 & 23,72 & 0,73 \\
Coimbra & $4,89^{* *}$ & 5771,11 & 12,08 & 0,80 \\
Capinópolis & $14,61^{* *}$ & 7134,62 & 12,16 & 0,93 \\
Castro & $4,65^{* *}$ & 5876,88 & 11,84 & 0,79 \\
\hline ** Significativo em nível de 1\% pelo teste F. & & \\
& ** Significant at 1\% level by F test.
\end{tabular}


OLIVEIRA et al.

A significância da interação $\mathrm{G} \times \mathrm{A}$ linear indica haver diferenças entre os coeficientes de regressão do grupo de genótipos avaliados (CRUZ e REGAZZI, 1997).

Na Tabela 3 são apresentadas as estimativas dos parâmetros de estabilidade e adaptabilidade obtidos pelas metodologias de PLAISTED e PETERSON (1959) e EBERHART e RUSSELL (1966). Tomando-se a média como o parâmetro fundamental para recomendação e comparação de desempenho de cultivares, verifica-se que as variedades BR HT2X, BR 205 e AGM 2010 foram as de melhor desempenho, produzindo acima de $7000 \mathrm{~kg} / \mathrm{ha}$. As variedades BR 201 e BR 206 também apresentaram médias elevadas, porém, pouco inferiores, não diferindo es- tatisticamente das três inicialmente citadas.

Entre as três variedades de desempenho superior, ressalta-se o fato de a variedade BR HT2X, apesar de ter média superior, apresentar baixa estabilidade. Esta imprevisibilidade pode ser verificada tanto pela metodologia de EBERHART e RUSSELL (1966), por meio dos desvios significativos, quanto pela alta contribuição para interação, quantificada pela estatística $\mathrm{Wi}$, proposta por PLAISTED e PETERSON (1959). Esta variedade, por apresentar média alta e coeficiente $\beta_{1 \mathrm{i}}$ superior a 1, deve ser indicada para ambientes de alta tecnologia (ou ambientes considerados favoráveis), em que os riscos proporcionados por fatores incontroláveis são minimizados.

Tabela 2 - Resultado da análise de variância conjunta para a característica produção de matéria seca degradável no rúmen

Table 2 - $\quad$ ANOVA combined result for the rumen degradable dry matter yield characteristic

\begin{tabular}{|c|c|c|c|c|}
\hline$\overline{\mathrm{FV}}$ & $\mathrm{GL}$ & SQ & QM & $\mathrm{F}$ \\
\hline$\underline{S V}$ & $D F$ & $S S$ & $S M$ & Ftest \\
\hline Bloco/Ambiente & 15 & $31.340 .975,19$ & $2.089 .397,15$ & - \\
\hline Block/Environment & & & & \\
\hline Ambiente & 4 & $59.421 .696,00$ & $14.855 .424,00$ & $7,11^{* *}$ \\
\hline $\begin{array}{l}\text { Environment } \\
\text { Genótipo }\end{array}$ & 7 & $119.467 .112,00$ & 17.066.730,00 & $6,92^{* *}$ \\
\hline $\begin{array}{l}\text { Genotype } \\
\text { Interação G X A } \\
\text { GxE interation }\end{array}$ & 28 & $69.011 .864,00$ & 2.464.709,50 & $2,01^{* *}$ \\
\hline $\begin{array}{l}\text { Amb./Gen. } \\
\text { Environ./Gen. }\end{array}$ & 32 & $128.433 .560,00$ & $4.013 .548,75$ & $3,26^{* *}$ \\
\hline $\begin{array}{l}\text { Ambiente linear } \\
\text { Linear environment }\end{array}$ & 1 & $59.421 .728,00$ & $59.421 .728,00$ & $48,40^{* *}$ \\
\hline $\begin{array}{l}\mathrm{G} \times \mathrm{Amb} . \text { linear } \\
\text { Gx Linear environ. }\end{array}$ & 7 & $20.878 .072,00$ & $2.982 .581,75$ & $2,43^{*}$ \\
\hline $\begin{array}{l}\text { Desvio combinado } \\
\text { Combined deviation }\end{array}$ & 24 & $48.133 .504,00$ & $2.005 .562,63$ & $1,63^{\mathrm{ns}}$ \\
\hline $\begin{array}{l}\text { DESVG-1 } \\
\text { Deviation for } G-1\end{array}$ & 3 & $3.722 .669,00$ & $1.240 .889,63$ & $1,01^{\mathrm{ns}}$ \\
\hline $\begin{array}{l}\text { DESVG-2 } \\
\text { Deviation for } G-2\end{array}$ & 3 & $4.935 .217,50$ & $1.645 .072,50$ & $1,34^{\mathrm{ns}}$ \\
\hline $\begin{array}{l}\text { DESVG-3 } \\
\text { Deviation for } G-3\end{array}$ & 3 & $1.611 .855,00$ & $537.285,00$ & $0,44^{\mathrm{ns}}$ \\
\hline $\begin{array}{l}\text { DESVG-4 } \\
\text { Deviation for } G-4\end{array}$ & 3 & $5.502 .212,00$ & $1.834 .070,63$ & $1,49^{\text {ns }}$ \\
\hline DESVG-5 & 3 & $9.529 .227,00$ & $3.176 .409,00$ & $2,59^{\text {ns }}$ \\
\hline $\begin{array}{l}\text { Deviation for } G-5 \\
\text { DESVG-6 }\end{array}$ & 3 & $17.384 .456,00$ & $5.794 .818,50$ & $4,72^{* *}$ \\
\hline $\begin{array}{l}\text { Deviation for } G-6 \\
\text { DESVG- } 7\end{array}$ & 3 & $539.788,00$ & $179.929,33$ & $0,15^{\mathrm{ns}}$ \\
\hline $\begin{array}{l}\text { Deviation for } G-7 \\
\text { DESVG- } 8\end{array}$ & 3 & $4.908 .082,00$ & $1.636 .027,38$ & $1,33^{\mathrm{ns}}$ \\
\hline $\begin{array}{l}\text { Deviation for } G-8 \\
\text { Resíduo }\end{array}$ & 105 & $128.898 .552,00$ & $1.227 .605,25$ & \\
\hline $\begin{array}{l}\text { Error } \\
\text { Média }\end{array}$ & & $6.424,55$ & & \\
\hline $\begin{array}{l}\text { Mean } \\
\mathrm{CV} \% \\
\end{array}$ & 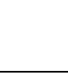 & 17,24 & & \\
\hline
\end{tabular}


234 Rev. bras. zootec.

Tabela 3 - Estimativa de parâmetros de estabilidade e adaptabilidade obtidos pelos métodos de Plaisted e Peterson e Eberhart e Russell para a característica produção de matéria seca degradável no rúmen

Table 3 - Estimate of stability and adaptability parameters obtained by the Plaisted and Peterson and Eberhart and Russell methods for the rumen degradable dry matter yield characteristic

\begin{tabular}{|c|c|c|c|c|c|c|}
\hline \multirow[b]{2}{*}{ Cultivar } & \multicolumn{2}{|c|}{ Plaisted e Peterson } & \multirow[b]{2}{*}{$\begin{array}{c}\text { Média }(\mathrm{kg} / \mathrm{ha})^{1} \\
\text { Mean }\end{array}$} & \multicolumn{3}{|c|}{ Eberhart e Russell } \\
\hline & Wi & $\mathrm{Wi}(\%)$ & & $\beta_{1 \mathrm{i}}$ & $\sigma_{d i}^{2}$ & $\mathrm{R}^{2}(\%)$ \\
\hline AGM-2010 & $134.442,14$ & 5,43 & $7.062,47 \mathrm{a}$ & $1,03 \mathrm{~ns}$ & $3.321,10$ & 68,07 \\
\hline BR-106 & $429.822,19$ & 17,37 & $5.291,65 \mathrm{c}$ & $0,02 * *$ & $104.366,81$ & 0,09 \\
\hline BR-201 & $89.269,44$ & 3,60 & $6.730,26 \mathrm{ab}$ & $0,66 \mathrm{~ns}$ & $-172.580,06$ & 66,80 \\
\hline BR-205 & $226.215,82$ & 9,14 & $7.338,31 \mathrm{a}$ & $1,33 \mathrm{~ns}$ & $151.616,36$ & 70,42 \\
\hline BR-206 & $350.162,75$ & 14,15 & $6.691,20 \mathrm{ab}$ & $1,18 \mathrm{~ns}$ & $487.200,94$ & 52,06 \\
\hline BR-HT2X & $845.999,44$ & 34,19 & $7.469,26 \mathrm{a}$ & $1,92 *$ & $1.141 .803,38 * *$ & 61,14 \\
\hline BR-92HD1 & $97.436,79$ & 3,94 & $5.651,08 \mathrm{bc}$ & $1,54 \mathrm{~ns}$ & $-261.918,98$ & 97,02 \\
\hline BR-CMS473 & $300.889,72$ & 12,16 & $5.162,13 \mathrm{c}$ & $0,32^{*}$ & $102.105,52$ & 13,07 \\
\hline
\end{tabular}

${ }^{1}$ Valores seguidos pela mesma letra não diferem $(P<0,05)$ pelo teste Tukey.

${ }^{*} \mathrm{e} * *$ Significativo em nível de 5 e $1 \%$, respectivamente, pelo teste $\mathrm{t}$, no caso de $\beta_{1 \mathrm{i}}$, e pelo teste $\mathrm{F}$, no caso de $\sigma_{d i}^{2}$.

1 Values followed by the same letters do not differ by Tukey test $(P<.05)$.

${ }^{*}$ and ${ }^{* *}$ Significant at 5 and $1 \%$ level, respectively, by $t$ test for $\beta_{1 i}$ case, and by $F$ test for $\sigma_{d i}^{2}$ case.

Assim, com vistas à recomendação mais ampla, destacam-se as variedades AGM 2010 e BR 205, as quais, além de média superior, apresentam adaptabilidade geral e alta previsibilidade fenotípica.

Também merece destaque o comportamento da variedade BR 106, que apresenta como estimativas de estabilidade e adaptabilidade $\beta_{1 \mathrm{i}}$ igual a $0,02 \mathrm{com}$ desvio não-significativo, apesar de o coeficiente de determinação ter sido igual a $9 \%$. Estas propriedades refletem as invariâncias do material, próprio de características relacionadas à rusticidade do material genético. Apesar de apresentar média inferior, superando apenas a BR CMS 473, trata-se de uma variedade que pode ser utilizada pelos agricultores. Suas propriedades de rusticidade e previsibilidade conferem a esta variedade características que a tornam de interesse para pequenos agricultores.

\section{Conclusões}

A variedade BR HT2X apresenta elevada produtividade, porém é a que mais contribui para a interação genótipo $\times$ ambiente e apresentou comportamento imprevisível. Recomenda-se sua utilização para alto nível tecnológico, em que os efeitos de condições adversas podem ser minimizados.

As variedades BR 205 e AGM 2010 destacam-se pela alta produtividade e são recomendadas como materiais de ampla adaptabilidade e alta previsibilidade.

As variedades BR CMS 473 e, principalmente, BR 106 apresentaram produtividades inferiores, porém, com comportamento previsível, demonstrando invariância de resposta à melhoria ambiental, o que caracteriza sua rusticidade.

\section{Referências Bibliográficas}

CARVALHO, L. P., COSTA, J. N., SANTOS, J. W. et al. 1995. Adaptabilidade e estabilidade em cultivares de algodão herbáceo. Pesq. Agrop. Bras., 30(2):207-213.

CRUZ, C. D., REGAZZI, A. J. 1997. Modelos Biométricos Aplicados ao Melhoramento Genético. Imprensa Universitária, Viçosa, MG, 390p.

CRUZ, C. D. 1997. Programa GENES: aplicativo computacional em genética e estatística. Viçosa, MG: Imprensa Universitária, $442 \mathrm{p}$.

EBERHART, S. A., RUSSELL, W. A. 1966. Stability parameters for comparing varieties. Crop Sci., 6:36-40.

HUNT, C. W., KESAR, W., HINMAM, D. D. et al. 1992. Effects of hybrid and ensiling with and without a microbial inoculant on the nutritional characteristics of whole-plant corn. $J$. Anim. Sci., 71(1):38-43.

NOCEK, J. E. 1988. In situ and other methods to estimate ruminal protein and energy digestibility: a review. J. Dairy Sci., 71(8):2051-2069.

OLIVEIRA, J. S., BRAGA, R. A. N., LOPES, F. C. F. et al. Avaliação da qualidade da planta de milho para silagem. In. REUNIÃO ANUAL DA SOCIEDADE BRASILEIRA DE ZOOTECNIA, 34, 1997, Juiz de Fora, MG. Anais... Juiz de Fora: SBZ, 1997. p.161.

PLAISTED, R. L., PETERSON, L. C. 1959. A technique for evaluating the ability of selections to yield consistently in different locations and seasons. Amer. Potato J., 36:381-385.

ROTH, G., UNDERSANDER, D. 1995. Corn silage production, management, and feeding. American Society of Agronomy, Madison, WI, 42p.

SILVA, D. J. 1990. Análise de alimentos: métodos químicos e biológicos. Imprensa Universitária, Viçosa, MG. 165p.

SILVA, F. G., ANUNCIAÇÃO FILHO, C. J., TABOSA, J. N. 1995. Estabilidade da produção de grãos de arroz irrigado nos Estados de Alagoas e de Pernambuco. Pesq. Agrop. Bras., 30(3):347-351.
Recebido em: 27/03/98

Aceito em: 20/08/98 